\title{
RECENSÃO DO LIVRO IMAGES OF IMMIGRANTS AND REFUGEES IN WESTERN EUROPE. MEDIA REPRESENTATIONS, PUBLIC OPINION, AND REFUGEES EXPERIENCES
}

\author{
BOOK REVIEW OF IMAGES OF IMMIGRANTS AND REFUGEES IN WESTERN EUROPE. \\ MEDIA REPRESENTATIONS, PUBLIC OPINION, AND REFUGEES EXPERIENCES
}

Fábio Ribeiro

Centro de Estudos de Comunicação e Sociedade, Universidade do Minho, Portugal / Universidade de Trás-os-Montes e Alto Douro, Portugal

\begin{abstract}
d'Haenens, L., Willen, J. \& Heinderyckx, F. (Eds.) (2019). Images of immigrants and refugees in Western Europe. Media representations, public opinion, and refugees' experiences. Lovaina: Leuven University Press.
\end{abstract}

Uma criança, com roupa amarrotada e suja, observa um muro imponente de grades e de arame farpado. Não consegue ultrapassar aquele obstáculo e, por isso, parece resignada. Mesmo sem qualquer legenda, imediatamente nos ocorre que aquela fotografia terá sido captada num qualquer campo de refugiados ou numa zona fronteiriça vedada à circulação de pessoas. E assim se dá o mote à capa do livro Images of immigrants and refugees in Western Europe. Media representations, public opinion, and refugees' experiences (2019), de Leen d'Haenens, Willem Joris e François Heinderyckx, que reúne o trabalho de investigadores sobre as implicações dos movimentos migratórios do ponto de vista comunicacional, mediático e sociológico, no contexto europeu.

A promoção da multiculturalidade está na génese da União Europeia, o que sugere "uma tela que recupera memórias, evidencia culturas e identidades, potencia discussões, reivindica diálogos construtivos e transformadores" (Silva, Cabecinhas \& Evans, 2019, p. 7). Aliás, na agenda das questões políticas europeias, as migrações estão permanentemente no discurso dos altos representantes governativos. No entanto, são os movimentos migratórios ilegais que preocupam mais as autoridades. Neste sentido, a atual crise migratória na Europa, que conheceu o período mais crítico a partir de 2015 , "já é considerada a maior deslocação de pessoas, motivada por conflitos armados, que ocorreu depois da Segunda Guerra Mundial" (Abdo, Cabecinhas \& Brites, 2019, p. 17). No livro que serve de base a esta recensão, os autores referem que a atual crise se relaciona com as manifestações que conduziram à chamada Primavera Árabe, um acontecimento que apenas alguns anos mais tarde desencadearia um êxodo de pessoas, sem precedentes, de zonas como a Síria, Líbano, Afeganistão e Egito, entre outros países. 
Muitas destas revoluções, que pretendiam derrubar ditadores, não se consolidaram com o tempo, pelo que significaram o regresso de dificuldades económicas e instabilidades políticas. O Egito é um desses casos. Na sequência da recente morte do antigo presidente, Hosni Mubarak, a 25 de fevereiro de 2020, que esteve no poder durante 30 anos, o jornal português Público explicava bem esta ideia de uma certa revolução de Pirro: "a Primavera árabe que o [Mubarak] depôs, não aguentou tanto tempo" (Fernandes, 2020).

Do ponto de vista histórico e demográfico recente, a problemática das migrações, nomeadamente aquelas que se referem a pessoas que procuram abandonar os países de origem sem qualquer documentação legal que lhes permita viver noutro, conhece extensões à escala mundial. Saskia Sassen (2016), uma das académicas mais reconhecidas a nível mundial na área da Sociologia do Desenvolvimento e da Demografia, considera que existem três fluxos migratórios decisivos para a compreensão deste drama profundamente atual: 1) na América Central, onde crianças e adolescentes que, por sua conta e risco, procuram um refúgio num país estrangeiro; 2) no Sudeste Asiático, com a crise de refugiados que se desenha desde Mianmar, Tailândia e Malásia, rumo à Austrália e Nova Zelândia; 3) na Europa Mediterrânica, na ressaca da crise dos países petrolíferos, a partir de 2015 .

Alguns sinais diplomáticos parecem reforçar a ideia de uma Europa atenta a este drama. A 29 de junho de 2018 , os líderes europeus chegaram a um entendimento no sentido de resgatar refugiados para território europeu, transferindo-os para "centros de controlo" dispersos pelos diversos Estados-membros. Segundo o jornal inglês The Guardian, embora o acordo tenha sido alcançado depois de intensas conversações, ainda hoje se discute a relevância deste acordo, sobretudo no sempre complexo tema da distribuição das quotas de refugiados por cada país (Henley, 2018). Neste quadro de permanente tensão geopolítica, alguns acontecimentos recentes não ajudam à estabilização de políticas europeias. Em fevereiro de 2020, o presidente turco Recep Tayyip Erdogan decidiu suspender o controlo das fronteiras do país, permitindo que cidadãos sírios conseguissem chegar à fronteira europeia. Erdogan defendia que a Europa não estava a cooperar convenientemente com a Turquia nesta questão (Turquia abre as portas da Europa aos refugiados. NATO solidária, 2020). Como resposta a esta decisão drástica da Turquia, a Guarda Costeira grega dispersou com tiros a chegada dos migrantes que tinham atravessado o território turco (Guarda costeira grega dispara para afastar migrantes, 2020).

Tendo em conta a atualidade desta questão e a imprevisibilidade de antecipar cenários concretos no xadrez diplomático, a obra que serve de base a esta análise oferece uma perspetiva distinta ao debate político, legal, a partir de uma perspetiva eminentemente comunicacional e mediática. Como refere Vliegenthart (2015), é pedido aos cientistas em Comunicação a inclusão de uma terceira dimensão de análise no tema das migrações, a par das atitudes culturais e das políticas públicas: a atuação dos média. Do ponto de vista da investigação em Ciências da Comunicação, sobram exemplos que confirmam este apelo. Diversos estudos têm abordado o papel dos refugiados como "objetos da violência simbólica" (Butler, 2004) ou de "informação precária" (Wall, Campbell 
\& Janbek, 2015). Através de uma modesta amostra', facilmente se percebe o interesse da comunidade académica pelo tema, designadamente nas publicações científicas com maior fator de impacto a nível mundial no ranking Scimago/Scopus ${ }^{2}$. A revista $\mathrm{New} \mathrm{Me}-$ dia and Society, a segunda mais bem cotada, apresenta 61 artigos que se poderiam enquadrar nesta temática, refletindo, por exemplo, sobre a islamofobia relativamente aos refugiados (Poole, Giraud \& de Quincey, 2020) ou o "pesadelo do multiculturalismo" (Nortio, Niska, Renvik \& Jasinskaja-Lahti, 2020). A revista Digital Journalism apresenta 23 trabalhos recentes nesta área, nomeadamente sobre a utilização de imagens virtuais na cobertura noticiosa dos refugiados (Mast \& Hanegreefs, 2015), enquanto a última deste ranking das dez mais cotadas, Political Communication, contém 54 artigos onde se poderá encontrar reflexões como a crise humanitária na Somália e a resposta da comunidade internacional (Livingston \& Eachus, 2010).

Este livro, para além de se constituir num contributo atual e documentado, junta-se a todo este esforço de reflexão científica sobre, genericamente, migrações e refugiados. Um certo senso comum coloca o termo "refugiado" na perspetiva ilegal da migração, envolta em risco e submetida a perigos constantes. No entanto, apesar de nem todos os migrantes serem refugiados, nesta aceção negativa do termo, os autores optam por não distinguir os dois conceitos.

Este livro procura responder a quatro desafios: discutir políticas de imigração e integração na Europa; avaliar as representações mediáticas sobre refugiados; medir os sedimentos pelos quais se consolida a opinião pública sobre migrantes; apresentar relatos e experiências de cidadãos que, inseridos nestas condições, procuram uma vida melhor no velho continente. Deste modo, cada um destes desafios aparece na obra sob a forma de uma parte autónoma, num total de 10 capítulos, de mais de uma dezena de investigadores maioritariamente belgas e suecos. Como se irá perceber mais à frente, existe um certo excesso de protagonismo da reflexão em torno dos Países Baixos e da Suécia, um facto que estará naturalmente relacionado com a proveniência dos investigadores que participam no livro, integrados no projeto "Images of immigrants in the media: thought-provoking effects" (IM²MEDIATE), que esteve em curso na Universidade de Lovaina, na Bélgica, entre 2015 e 2019.

O primeiro capítulo funciona como prefácio e síntese das 209 páginas que compõem o livro. Leen d'Haenens e Willem Joris acenam, desde logo, com uma ideia tão óbvia quanto crua: "não há soluções simples para a crise migratória na Europa" (p. 7). Contudo, os autores notam que o número de pessoas que tenta, pela via legal, obter autorização para trabalhar na União Europeia diminui todos os anos - cerca de 600 mil, em 2018. A maioria dos candidatos é do sexo masculino (67\%). Os autores deixam os leitores a especular sobre este decréscimo, que pode residir na burocracia, no descrédito

\footnotetext{
' Os dados foram recolhidos em março de 2020.

${ }^{2} \mathrm{Na}$ lista das dez publicações com maior fator de impacto constam as seguintes: 1) Internet Research; 2) New Media and Society; 3) Information Communication and Society; 4) Communication Theory; 5) Digital Journalism; 6) Journal of Communication; 7) Journal of Advertising; 8) Human Communication Research; 9) Media Psychology; 10) Political Communication. Retirado de https://www.scimagojr.com/journalrank.php?area=330o\&category=3315
} 
pelas instituições públicas ou nos intensos sinais políticos contraditórios que se materializam nos discursos xenófobos e nacionalistas de Salvini, na Itália, ou de Viktor Orbán, na Hungria, entre tantos exemplos que poderiam ser elencados. De qualquer maneira, d'Haenens e Joris explicam por que razão a Bélgica e a Suécia surgem como estudos de caso preferenciais neste livro. Entre outras razões, referem que "ambos os países enfrentam realidades idênticas no que concerne ao número de refugiados que acolhem" (p. 13), estabelecendo políticas duradoras capazes de promover a tolerância e abertura junto dos migrantes.

Na primeira das quatro partes do livro, discute-se as políticas de imigração e integração na Europa, num único capítulo. Partindo do caso belga e sueco, Paul Puschmann, Ebba Sundin, David De Coninck e Leen d'Haenens defendem que estes países apostam numa sociedade multicultural onde a extrema-direita apologista do nacionalismo exacerbado não tem grande sucesso: "a integração de imigrantes presta-se ao desenvolvimento de políticas que contrariam a segregação e a discriminação em certos setores da sociedade" (p. 34).

$\mathrm{Na}$ segunda parte do livro encontra-se a reflexão mais alargada. Quatro textos analisam, sob vários prismas, as representações dos média sobre migração e integração. No primeiro, através de uma análise de conteúdo das notícias publicadas sobre migrantes e refugiados, entre 2015 e 2017 , em diversos jornais belgas e suecos, percebe-se que a cobertura mediática pode ser bastante distinta. Os jornais suecos publicam artigos em maior número e mais extensos. A marca comum consiste na atribuição do papel de "bom" e "mau" ao refugiado, com algumas peças que destacam os "sonhos" que os movem.

O segundo texto, assinado por Valériane Mistiaen, analisou a cobertura mediática da televisão de língua francesa - RTL-TVI (pública) e La Une (comercial). Utilizando uma análise lexical de 300 notícias, de 2015 , concluiu-se que não existem substanciais diferenças entre operadores de serviço público e privado, isto é, ambos oferecem uma visão estereotipada destes grupos minoritários, o que contraria estudos anteriores como os de De Bens's (2004). Ainda assim a televisão comercial apresenta tipicamente reportagens sobre os problemas de criminalidade associados aos refugiados. O possível contributo positivo - social ou económico - da integração destas pessoas nunca acaba por ser abordado.

O terceiro texto, da autoria de Lutgard Lams, aborda um dos momentos mais traumáticos que a Europa enfrentou, quando em 2015 se deparou com uma crise migratória sem precedentes. Segundo contas da BBC (Migrant crisis: migration to Europe explained in seven charts, 2016), mais de um milhão de pessoas tentaram nessa altura chegar ao continente europeu, por via aérea - mas sobretudo marítima, de forma ilegal, em embarcações precárias e sobrelotadas, depois do escalar do conflito na Síria, mas também devido a situações dramáticas de guerra no Afeganistão ou na Eritreia. Observando alguns jornais dos Países Baixos, e a forma como estes retrataram esta crise em particular, Lams identificou abordagens diferentes na "semântica jornalística": o De Volkskrant (Holanda) e o De Morgen (Bélgica) colocaram, muitas vezes, a tónica no papel positivo da União Europeia, embora este último não tenha deixado de fazer algumas críticas, apontando o dedo à chanceler alemã, Angela Merkel. $O$ autor concluiu ainda que estes 
jornais retratam os refugiados como indivíduos alienados da realidade, impotentes e distantes das decisões políticas.

Por fim, o quarto texto dedica-se a um estudo metajornalístico. Os autores - Stefan Mertens, Leen d'Haenens, Rozane De Cock e Olivier Standaert - analisaram os discursos de jornalistas de 24 países ocidentais, com a exceção da Coreia do Sul, sobre os diversos índices de tolerância, acompanhamento, intervenção, colaboração e integração de migrantes e refugiados nos respetivos países. Ao contrário do que esperavam encontrar, os investigadores concluíram que países com tradições jornalísticas multiculturais e tolerantes têm um menor número de políticas de integração. Outro ponto saliente desta análise reside no facto de o discurso da maioria dos jornalistas se inscrever numa tradição normativa, de promoção da tolerância e diversidade, o que depois acaba por contrariar as conclusões observadas em capítulos anteriores.

$\mathrm{Na}$ terceira parte do livro, debate-se essencialmente a forma como a opinião pública se envolve nesta problemática. No primeiro texto, David De Coninck, Hanne Vandenberghe e Koen Matthijs estudaram as representações mentais e sociais de cidadãos belgas e suecos, entre os 18 e os 65 anos. Na Bélgica, os cidadãos tendem a defender que as televisões comerciais provocam sentimentos negativos em relação aos refugiados, ao contrário do que sucede com o serviço público. Deste modo, os investigadores confrontaram essa perceção sobre os média com as opiniões individuais e encontraram diferenças significativas. Percebe-se, por isso, que nem sempre os média produzem efeitos determinantes e influenciam decisivamente a opinião pública. É este o sentido de estudos recentes (Correia, Jerónimo \& Gradim, 2019), ao proporem que a teoria do agenda setting está completamente desatualizada.

No texto seguinte, três autores demonstram a existência de "bolhas de informação", capazes de filtrar perceções públicas, o que se torna curioso, porque pode precisamente contrariar o estudo anterior. Os investigadores mediram as atitudes de seis mil inquiridos através de um inquérito online perante notícias filtradas para determinar eventuais condicionamentos interpretativos e concluíram que existe uma tendência para uma validação de conteúdos que se aproximam das crenças individuais. Ainda assim, admitem a existência de uma "opinião pública dividida (se não negativa) e um nível genericamente elevado de pouca informação ou ausência total da mesma sobre este assunto, e uma tendência para subestimar números oficiais, associando refugiados ao crime e terrorismo" (p. 155).

Por último nas reflexões sobre este terceiro tema, um texto que se aproxima bastante do contributo anterior. Willem Joris e Rozane De Cock procuram perceber se um determinado posicionamento jornalístico condiciona a atitude de uma pessoa. Num estudo que envolveu mil e quatrocentos cidadãos belgas, os investigadores concluíram, entre outros aspetos, que o efeito de frame $e^{3}$ não se concretizou, uma vez que depois de confrontados com uma perspetiva contrária à sua opinião, os inquiridos mantiveram as suas posições relativamente a um determinado assunto. De um modo mais impressivo,

${ }^{3}$ Isto é, o efeito de exposição sistemática a um conjunto de imagens e conteúdos. 
os autores consideram que nem mesmo o nível de consciência sobre o tema dos refugiados ou de grau de escolaridade interferem nesta correlação.

Em último lugar, a quarta parte deste livro apresenta, num único capítulo, o resultado de uma investigação sobre discursos e relatos dos próprios refugiados. Através do contacto com várias agências e organizações não governamentais, os investigadores estudaram as perceções de 44 refugiados - 24 vindos da Síria, 11 do Afeganistão e nove do Iraque -, residentes na Bélgica desde 2015. Utilizando questionários online e entrevistas em profundidade, os autores concluíram que os refugiados se sentem representados, invariavelmente, como "vítimas" pelos meios de comunicação mainstream, lamentando a falta de notícias sobre o contributo positivo que poderiam oferecer às economias e sociedades europeias, uma linha conceptual já abordada anteriormente no livro. Os inquiridos demonstraram, ainda assim, que sentem esperança no papel que os média possam desempenhar para alterar este paradigma negativo, um fator que poderá ser determinante para condicionar ações políticas mais efetivas de integração.

No final do livro surge o capítulo de François Heinderyckx, reconhecido académico, que se dedica, numa espécie de posfácio, a sistematizar o percurso da obra. O autor lembra um aspeto que parece pouco debatido no livro e que se relaciona com a facilidade com que os partidos políticos extremistas - da esquerda à direita - recorrem à temática dos refugiados para vincar as suas opiniões: "migrantes, refugiados e outras minorias visíveis provaram ser os bodes-expiatórios perfeitos para dilacerar a atualidade: a crise económica, desemprego, pobreza, criminalidade, terrorismo, ameaças de saúde, homogeneização cultural" (p. 199). O contributo de Heinderyckx torna-se ainda mais relevante neste documento porque sinaliza áreas não contempladas nos capítulos anteriores. Por isso, deixa algumas recomendações para uma mudança de paradigma: evitar o uso de clichés na representação mediática sobre migrantes, abandonar a perspetiva negativista de um grupo de "condenados", e uma maior consciência da classe jornalística para uma cobertura mais diversificada e interessante para mudar mentalidades.

Pertinente em termos teóricos, refletindo um problema da máxima atualidade, o livro Images of immigrants and refugees in Western Europe. Media representations, public opinion, and refugees' experiences torna-se num documento científico particularmente relevante pela robustez metodológica que revela, onde várias técnicas de investigação são ensaiadas, desde o inquérito ao grupo de foco. Este facto pode converter esta obra numa ferramenta importante de estudo para estudantes universitários e académicos em geral. A disponibilização do livro em acesso aberto, sem custos, no site da Leuven University Press ${ }^{4}$ também se presta a este propósito.

\section{Agradecimentos}

Este trabalho é apoiado por fundos nacionais através da FCT - Fundação para a Ciência e a Tecnologia, I.P., no âmbito do projeto UIDB/00736/2020.

${ }_{4}^{4}$ Disponível em https://lup.be/products/119590 


\section{REFERÊNCIAS}

Abdo, C., Cabecinhas, R. \& Brites, M. J. (2019). Crise migratória na Europa: os media e a construção da imagem dos refugiados. In Z. Pinto-Coelho; S. Marinho \& T. Ruão (Eds.), Comunidades, participação e regulação. VI Jornadas Doutorais, Comunicação Q Estudos Culturais (pp. 71-83). Braga: CECS.

Butler, J. (2004). Precarious life: the powers of mourning and violence. Nova lorque: Verso.

Correia, J., Jerónimo, P. \& Gradim, A. (2019). Fake news: emoção, crença e razão na partilha seletiva em contextos de proximidade. Brazilian Journalism Research, 15(3), 626-651. https://doi.org/10.25200/BJR. v15n3.2019.1219

De Bens, E. (2004). Belgium. In M. Kelly; G. Mazzoleni \& D. McQuail (Eds.), The media in Europe. The Euromedia Research Group (pp. 16-30). Londres: SAGE Publications.

Fernandes (2020, 25 de fevereiro). Hosni Mubarak, o ditador que viveu o suficiente para ver derrotada a revolução que o depôs. Público. Retirado de https://www.publico.pt/2020/02/25/mundo/noticia/ hosni-mubarak-ditador-viveu-suficiente-derrotada-revolucao-depos-1905464

Guarda costeira grega dispara para afastar migrantes (2020, 03 de março). Jornal de Notícias. Retirado de https://www.jn.pt/mundo/videos/guarda-costeira-grega-dispara-para-afastar-migrantes-11883839.html

Henley, J. (2018, 29 de fevereiro). EU migration deal: what was agreed and will it work?. The Guardian. Retirado de https://www.theguardian.com/world/2018/jun/29/eu-summit-migration-deal-key-points

Livingston, S. \& Eachus, T. (2010). Humanitarian crises and U.S. foreign policy: Somalia and the CNN effect reconsidered. Political Communication, 12(4), 413-429. https://doi.org/10.1080/10584609.1995.9963087

Mast, J. \& Hanegreefs, S. (2015). When news media turn to citizen-generated images of war. Digital Journalism, 3(4), 594-614. https://doi.org/10.1080/21670811.2015.1034527

Migrant crisis: migration to Europe explained in seven charts (2016, 04 de março). BBC News. Retirado de https://www.bbc.com/news/world-europe-34131911

Nortio, E., Niska, M., Renvik, T. A. \& Jasinskaja-Lahti, I. (2020). 'The nightmare of multiculturalism': Interpreting and deploying anti-immigration rhetoric in social media. New Media Q Society, oo(o), 1-19. https://doi.org/10.1177/1461444819899624

Poole, E., Giraud, E. H. \& de Quincey, E. (2020). Tactical interventions in online hate speech: The case of \#stoplslam. New Media o. Society, oo(o), 1-28. https://doi.org/10.1177/1461444820903319

Sassen, S. (2016). A massive loss of habitat new drivers for migration. Sociology of Development, 2(2), 204233. https://doi.org/10.1525/sod.2016.2.2.204

Silva, A., Cabecinhas, R. \& Evans, R. (2019). Culturas, memórias, diálogos em construção. Comunicação e Sociedade [Vol. Especial], 7-11. https://doi.org/10.17231/comsoc.0(2019).3056

Turquia abre as portas da Europa aos refugiados. NATO solidária (2020, 27 de fevereiro). Diário de Notícias. Retirado de https://www.dn.pt/mundo/turquia-abre-as-portas-da-europa-aos-refugiados-e-lancaofensiva-na-siria-11866974.html

Vliegenthart, R. (2015). Mediamacht. De interactie tussen media, publiek en politiek. In J. Bardoel \& H. Wijfjes (Eds.), Journalistieke cultuur in Nederland (pp.221-236). Amsterdão: Amsterdam University Press.

Wall, M., Otis Campbell, M. \& Janbek, D. (2017). Syrian refugees and information precarity. New Media Q Society, 19(2), 240-254. https://doi.org/10.1177/1461444815591967 


\section{NOTA BIOGRÁFICA}

Fábio Ribeiro é Professor Auxiliar na Universidade de Trás-os-Montes e Alto Douro (UTAD), em Vila Real (Portugal). Ensina nas áreas do Jornalismo (imprensa, rádio e televisão) e sobre Sociologia da Comunicação. Membro integrado do Centro de Estudos de Comunicação e Sociedade da Universidade do Minho, desenvolve investigação sobre média, participação, comunicação de ciência e Estudos Radiofónicos. Desde 2017, é vice-coordenador do Grupo de Trabalho "Rádio e Meios Sonoros" da Associação Portuguesa de Ciências da Comunicação (Sopcom).

ORCID: https://orcid.org/oooo-0001-8071-6145

Email: fabior@utad.pt

Morada: Universidade de Trás-os-Montes e Alto Douro, Quinta de Prados, 5001801 Vila Real

Submetido: $18 / 03 / 2020$

Aceite: $03 / 07 / 2020$ 